\title{
HUBUNGAN ANTARA POLA KONSUMSI DAN AKTIVITAS FISIK DENGAN STATUS GIZI PADA LANSIA DI PANTI SOSIAL TRESNA WERDHA UNIT ABIYOSO YOGYAKARTA
}

\author{
Nurika Ismayanti, Solikhah \\ Fakultas Kesehatan Masyarakat, Universitas Ahmad Dahlan, Yogyakarta
}

\begin{abstract}
Background: Elderly Group is included into nutritional susceptible group because of specific feature causing this group easily affected by malnutrition. Age increasing in someone causes a low metabolism velocity. It can be solved by giving nutritional need adequate for elderly. Thus, paying attention to consumption pattern is an important thing to keep their nutritional status. Aside from giving a good nutrition, physical activity is also a thing that should be paid attention to in elderly. The aims of this research are for consumption pattern, physical activity, nutritional status, and relation between consumption pattern and physical activity with nutritional status in elderly in Panti Sosial Trena Werdha (PTSW) Unit Abiyoso Yogyakarta, at year 2011.
\end{abstract}

Methods: Cross sectional was chosen as the design of this research. Population in this research was all elderly in PTSW Unit Abiyoso Yogyakarta. Sample taken in this research was population that filled inclusion criteria established by the researcher, so that sample obtained 53 people. Instrument research used was direct measure and questionnaire interview, and analyze used was Chi square.

Results: Based on bi-variety test, there is no significant relation between consumption pattern and nutritional status, seen from $\mathrm{RP}=0,811$ with Confident Interval $0,479<R P<1,372$. And there is no significant relation between physical activity and nutritional status, seen from $R P=1,005$ with Confident Interval $0,638<R P<1,585$.

Conclusion: There is no significant relation between consumption patterns and physical activity with nutritional status in elderly in Panti Sosial Tresna Werdha (PSTW) Unit Abiyoso Yogyakarta, at year 2011.

Keywords: consumption patterns, physical activity, nutritional status

\section{PENDAHULUAN}

Badan Kesehatan Dunia (WHO) menyatakan bahwa penduduk lansia di Indonesia pada tahun 2020 mendatang sudah mencapai angka 11,34\% atau tercatat 28,8 juta orang, balitanya tinggal $6,9 \%$ yang menyebabkan jumlah penduduk lansia terbesar di dunia. ${ }^{1} \mathrm{Hal}$ ini mungkin terjadi akibat adanya perubahan pola makan dan gaya hidup penduduk Indonesia disamping perubahan struktur penduduk Indonesia. Perubahan struktur penduduk Indonesia ditandai dengan meningkatnya proporsi penduduk usia produktif dan lansia serta menurunnya proporsi penduduk balita. ${ }^{2}$ 
Keberhasilan pembangunan nasional suatu bangsa ditentukan oleh ketersediaan sumber daya manusia (SDM) yang berkualitas. ${ }^{3}$ Pencapaian pembangunan manusia yang diukur dengan Indeks Pembangunan Manusia (IPM) belum menunjukkan hasil yang menggembirakan. Pada tahun 2003, IPM Indonesia masih rendah yaitu berada pada peringkat 112 dari 174 negara, lebih rendah dari negara-negara tetangga. Rendahnya IPM ini dipengaruhi oleh rendahnya status gizi dan status kesehatan penduduk. ${ }^{4}$

Kelompok rentan gizi adalah kelompok masyarakat yang paling mudah menderita kelainan gizi, bila suatu masyarakat terkena kekurangan penyediaan makanan, dan lansia masuk ke dalam salah satu kelompok rentan gizi. Faktor yang dapat mempengaruhi kesehatan seseorang salah satunya adalah diet. Bertambahnya usia seseorang, menyebabkan kecepatan metabolisme tubuh cenderung turun. Permasalahan tersebut dapat diatasi dengan memberikan kebutuhan gizi yang adekuat untuk lansia.

Asupan makanan yang tidak seimbang juga dapat menyebabkan konsumsi yang berlebihan yang berhubungan dengan perubahan dalam gaya hidup yang akan berpengaruh terhadap munculnya berbagai penyakit tidak menular pada lansia. ${ }^{5}$ Selain pemberian nutrisi yang baik, aktivitas fisik juga merupakan hal yang perlu diperhatikan pada lansia. Olahraga teratur dan istirahat yang cukup dapat memperlambat penuaan jantung dan pembuluh darah serta menurunkan risiko penyakit jantung koroner. ${ }^{6}$

Peningkatan jumlah penduduk lanjut usia menjadi salah satu indikator keberhasilan pembangunan sekaligus sebagai tantangan dalam pembangunan. Apabila permasalahan tersebut tidak diantisipasi dari sekarang, maka tidak tertutup kemungkinan bahwa proses pembangunan akan mengalami berbagai hambatan. Hal tersebut menyebabkan permasalahan lanjut usia harus menjadi perhatian kita semua, baik pemerintah, lembaga masyarakat maupun masyarakat itu sendiri. ${ }^{1}$

Hasil observasi pendahuluan yang dilaksanakan pada tanggal 16 dan 21 Maret 2011 pada lansia di Panti Sosial Tresna Werdha (PSTW) Unit Abiyoso Yogyakarta, diketahui bahwa pola konsumsi lansia di Panti ini sudah bisa dikategorikan baik karena frekuensi makan mereka sudah tiga kali sehari dan melakukan aktivitas fisik seperti senam setiap hari. Berdasarkan hasil observasi pendahuluan tersebut, peneliti ingin mencoba melakukan penelitian mengenai hubungan antara pola konsumsi dan aktivitas fisik dengan status gizi pada lansia di Panti Sosial Tresna Werdha (PSTW) Unit Abiyoso Yogyakarta Tahun 2011.

\section{METODE PENELITIAN}

Jenis penelitian ini adalah observasional analitik dengan rancangan cross sectional. Dipilih rancangan ini karena setiap subyek hanya diobservasi sekali saja dan pengukuran variabel dilaksanakan pada saat itu juga. Penelitian Cross Sectional relatif mudah dilaksanakan karena ekonomis dari segi waktu, membutuhkan biaya yang tidak terlalu besar, dan hasilnya dapat diperoleh dengan cepat. Rancangan dari desain cross sectional adalah sebagai berikut : 7 


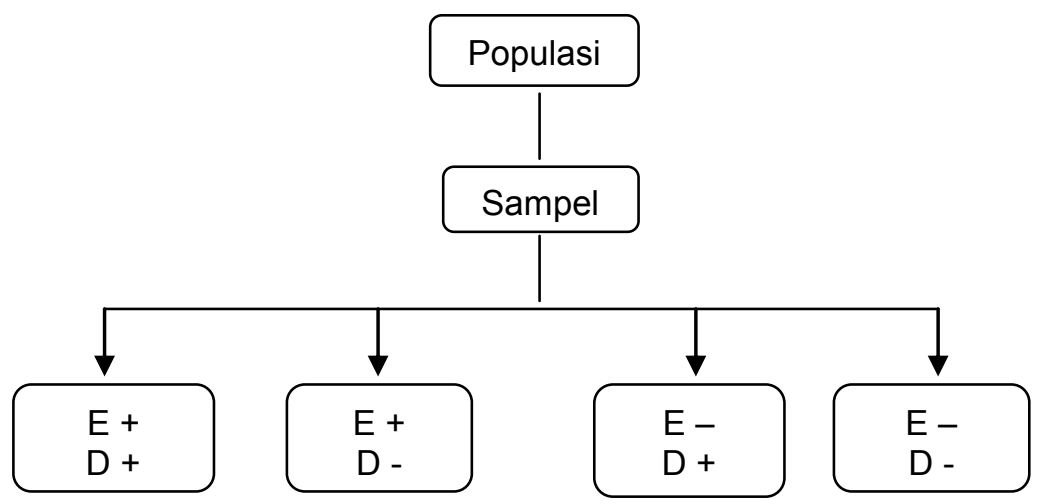

Keterangan:

$\mathrm{E}^{+}=$Terpapar/tidak baik

$\mathrm{D}^{+}=$Tidak baik

$\mathrm{E}^{-}=$Tidak terpapar/ baik

$D^{-}=$Baik

Gambar 1. Rancangan Desain Cross Sectional

\section{A. Populasi dan Sampel Penelitian}

Populasi dalam penelitian ini yaitu seluruh lansia yang ada di Panti Sosial Tresna Werdha (PSTW) Unit Abiyoso Yogyakarta yang berjumlah 120 orang. Sampel dalam penelitian ini diambil dari jumlah populasi yang memenuhi kriteria inklusi dan eksklusi yang ditetapkan oleh peneliti. Teknik pengambilan sampel yang digunakan adalah purposive sampling.

1) Kriteria inklusi yaitu:

a) Bersedia menjadi responden.

b) Berada di tempat saat penelitian berlangsung.

c) Tinggal di Panti Sosial Tresna Werdha Unit Abiyoso Yogyakarta.

2) Kriteria eksklusi, yaitu tidak bisa berkomunikasi dengan baik karena menderita gangguan psikologis.

Besar sampel yang diperlukan dalam penelitian ini ditentukan dengan menggunakan rumus :

$$
n=\frac{C^{2} x \frac{(p \cdot q)}{d^{2}}}{1+\left\{C^{2} x \frac{(p \cdot q)}{d^{2} N}\right\}}
$$


Keterangan:

$\mathrm{n} \quad=$ Jumlah sampel

$\mathrm{N} \quad=$ Besar populasi (120 Lansia)

C = Tingkat kepercayaan/ketepatan yang diinginkan peneliti $95 \%$

d $\quad=$ Tingkat presisi yang dipakai $10 \%$

$\mathrm{p} \quad=$ Proporsi $(\mathrm{P}=0,5)$

$q \quad=(1-p)$

$n=\frac{C^{2} x \frac{(p \cdot q)}{d^{2}}}{1+\left\{C^{2} x \frac{(p . q)}{d^{2} N}\right\}}$

$n=\frac{1,96^{2} \times \frac{(0,5.0,5)}{0,1^{2}}}{1+\left\{1,96^{2} \times \frac{(0,5 . ., 5)}{0,1^{2} 120}\right\}}$

$n=53,04=53$

Jumlah sampel yang digunakan dalam penelitian ini adalah sebesar 53 orang lansia.

\section{B. Analisis Data Penelitian}

1) Analisis Univariat

Analisis univariat dilakukan untuk mendeskripsikan variabel penelitian dengan tabel distribusi. Hasil pengolahan data akan disajikan dalam bentuk distribusi dan persentase dari tiap variabel.

2) Analisis Bivariat (tabulasi silang)

Analisis bivariat (tabulasi silang) dilakukan terhadap dua variabel yang diduga berhubungan atau berkorelasi. Output berupa Prevalen Rasio (PR) dan $P$ value. Nilai $P$ value merupakan peluang untuk mendapatkan hasil yang diperoleh bila hipotesis diterima. Analisis bivariat dilakukan pada masing-masing variabel untuk mengetahui hubungan yang diteliti dengan status gizi. Ada tidaknya perbedaan atau kemaknaan secara statistik ditunjukkan dari hasil perhitungan tabel silang $2 \times 2$, dan uji statistik yang digunakan adalah chi square. Tingkat kepercayaan yang digunakan $95 \%$ dan $P$ value $<0,05$, artinya Hipotesis akan bermakna jika $P<0,05$ dan atau confidence interval tidak mencakup angka satu. Analisis data menggunakan komputerisasi. 


\section{HASIL PENELITIAN DAN PEMBAHASAN}

\section{A. Hasil Penelitian}

\section{Gambaran Umum Lokasi Penelitian}

Panti Sosial Tresna Werdha (PSTW) Unit Abiyoso Yogyakarta merupakan panti sosial yang mempunyai tugas memberikan bimbingan dan pelayanan bagi lanjut usia terlantar. Lanjut usia diharapkan agar dapat hidup secara baik dan terawat dalam kehidupan masyarakat baik yang berada di dalam panti maupun yang berada di luar panti.

PSTW Unit Abiyoso ini memiliki luas $9.720 \mathrm{~m}^{2}$, jumlah lansia yang tinggal di PSTW ini berjumlah 120 orang, dan rata-rata lansia yang tinggal di panti ini sudah tidak mempunyai keluarga lagi. Program pelayanan di PSTW Unit Abiyoso ini, terdiri dari program pelayanan rutin (reguler), program pelayanan subsidi silang, program day care service, program home care, program trauma service, dan program tetirah (tinggal sementara).

\section{Gambaran Sampel Penelitian}

\section{a. Jenis Kelamin Responden}

Tabel 1. Distribusi Frekuensi Responden Berdasarkan Jenis Kelamin di PSTW Unit Abiyoso, Yogyakarta Tahun 2011

\begin{tabular}{lcc}
\hline \multicolumn{1}{c}{ Jenis Kelamin } & Jumlah & Persentase $(\%)$ \\
\hline Laki-laki & 15 & 28,3 \\
\hline Perempuan & 38 & 71,7 \\
\hline Total & 53 & 100,0 \\
\hline
\end{tabular}

Pada Tabel 1 dapat dilihat bahwa berdasarkan hasil penelitian di PSTW Unit Abiyoso dari 53 responden yang diteliti karakteristik responden yang berjenis kelamin perempuan lebih banyak dijadikan sampel yaitu 38 responden $(71,7 \%)$, sedangkan responden yang berjenis kelamin laki-laki yaitu 15 responden $(28,3 \%)$. 


\section{b. Pola Konsumsi}

Tabel 2.Distribusi Frekuensi Responden Berdasarkan Tingkat Konsumsi Energi dalam 2x24 Jam di PSTW Unit Abiyoso, Yogyakarta Tahun 2011

\begin{tabular}{lcc}
\hline \multicolumn{1}{c}{ Tingkat Konsumsi Energi } & Jumlah & Persentase (\%) \\
\hline Tidak baik & 15 & 28,3 \\
\hline Baik & 38 & 71,7 \\
\hline Total & 53 & 100,0 \\
\hline
\end{tabular}

Pada Tabel 2 dapat dilihat bahwa berdasarkan hasil penelitian di PSTW Unit Abiyoso dari 53 responden yang diteliti, sebanyak 15 responden $(28,3 \%)$ memiliki tingkat konsumsi untuk energi yang tidak baik, sedangkan 38 responden $(71,7 \%)$ memiliki tingkat konsumsi energi dengan kategori baik.

\section{c. Aktivitas Fisik}

Tabel 3. Distribusi Frekuensi Responden Berdasarkan Aktivitas Fisik di PSTW Unit Abiyoso, Yogyakarta Tahun 2011

\begin{tabular}{lcc}
\hline \multicolumn{1}{c}{ Aktivitas Fisik } & Jumlah & Persentase (\%) \\
\hline Tidak berolahraga & 16 & 30,2 \\
\hline Berolahraga & 37 & 69,8 \\
\hline Total & 53 & 100,0 \\
\hline
\end{tabular}

Pada Tabel 3 dapat dilihat bahwa berdasarkan hasil penelitian di PSTW Unit Abiyoso dari 53 responden yang diteliti, sebanyak 16 responden $(30,2 \%)$ dengan kategori tidak berolahraga, sedangkan yang berolahraga ada sebanyak 37 responden $(69,8 \%)$.

\section{d. Status Gizi}

Tabel 4. Distribusi Frekuensi Responden Berdasarkan Status Gizi di PSTW Unit Abiyoso, Yogyakarta Tahun 2011

\begin{tabular}{lcc}
\hline \multicolumn{1}{c}{ Status Gizi } & Jumlah & Persentase (\%) \\
\hline Tidak baik & 33 & 62,3 \\
\hline Baik & 20 & 37,7 \\
\hline Total & 53 & 100,0 \\
\hline
\end{tabular}


Pada Tabel 4 dapat dilihat bahwa berdasarkan hasil penelitian di PSTW Unit Abiyoso dari 53 responden yang diteliti, sebanyak 33 responden $(62,3 \%)$ memiliki status gizi yang tidak baik, sedangkan yang memiliki status gizi yang baik ada 20 responden $(37,7 \%)$.

\section{Analisis Hubungan Antar Variabel (Bivariat)}

\section{a. Hubungan Antara Pola Konsumsi dengan Status Gizi}

Tabel 5. Hubungan Antara Pola Konsumsi dengan Status Gizi pada Lansia di PSTW Unit Abiyoso, Yogyakarta Tahun 2011

\begin{tabular}{|c|c|c|c|c|c|c|c|c|}
\hline \multirow{3}{*}{ Pola Konsumsi } & \multicolumn{4}{|c|}{ Status Gizi } & \multirow{2}{*}{\multicolumn{2}{|c|}{ Total }} & \multirow{3}{*}{$\begin{array}{c}\mathrm{P} \\
\text { value }\end{array}$} & \multirow{3}{*}{$\begin{array}{c}\mathrm{RP}(95 \% \\
\mathrm{Cl})\end{array}$} \\
\hline & \multicolumn{2}{|c|}{ Tidak baik } & \multicolumn{2}{|c|}{ Baik } & & & & \\
\hline & $\mathrm{N}$ & $\%$ & $\mathrm{~N}$ & $\%$ & $\mathrm{~N}$ & $\%$ & & \\
\hline Tidak baik & 8 & 24,2 & 7 & 35,0 & 15 & 28,3 & & \\
\hline Baik & 25 & 75,8 & 13 & 65,0 & 38 & 71,7 & 0,399 & $\begin{array}{c}0,811(0,479 \\
-1,372)\end{array}$ \\
\hline Total & 33 & 100,0 & 20 & 100,0 & 53 & 100,0 & & \\
\hline
\end{tabular}

Hasil uji statistik diperoleh nilai RP $=0,811$ dengan Confident Interval $0,479<\mathrm{RP}<1,372$ yang mencakup angka satu dengan $\mathrm{P}$ value $=0,399$. Hal ini menunjukkan tidak ada hubungan antara pola konsumsi dengan status gizi. Hasil $\mathrm{RP}=0,811$ menunjukkan bahwa orang yang pola konsumsinya tidak baik memiliki peluang untuk mengalami status gizi yang tidak baik 0,811 kali dari pada orang yang pola konsumsinya baik dan secara statistik tidak bermakna. 
b. Hubungan Antara Aktivitas Fisik dengan Status Gizi

Tabel 6. Hubungan Antara Aktivitas Fisik dengan Status Gizi pada Lansia di PSTW Unit Abiyoso, Yogyakarta Tahun 2011

\begin{tabular}{|c|c|c|c|c|c|c|c|c|}
\hline \multirow{3}{*}{$\begin{array}{l}\text { Aktivitas } \\
\text { Fisik }\end{array}$} & \multicolumn{4}{|c|}{ Status Gizi } & \multirow{2}{*}{\multicolumn{2}{|c|}{ Total }} & \multirow{3}{*}{$\begin{array}{c}\mathrm{P} \\
\text { value }\end{array}$} & \multirow{3}{*}{$\begin{array}{c}\mathrm{RP} \\
(95 \% \mathrm{Cl})\end{array}$} \\
\hline & \multicolumn{2}{|c|}{ Tidak baik } & \multicolumn{2}{|c|}{ Baik } & & & & \\
\hline & $\mathrm{N}$ & $\%$ & $\mathrm{~N}$ & $\%$ & $\mathrm{~N}$ & $\%$ & & \\
\hline $\begin{array}{l}\text { Tidak ber- } \\
\text { olahraga }\end{array}$ & 10 & 30,3 & 6 & 30,0 & 16 & 30,2 & & \\
\hline Berolahraga & 23 & 69,7 & 14 & 70,0 & 37 & 69,8 & 0,981 & $\begin{array}{c}1,005 \\
(0,638- \\
1,585)\end{array}$ \\
\hline Total & 33 & 100,0 & 20 & 100,0 & 53 & 100,0 & & \\
\hline
\end{tabular}

Hasil uji statistik diperoleh nilai RP $=1,005$ dengan Confident Interval $0,638<R P<1,585$ yang mencakup angka satu dengan $P$ value $=0,981$. Hal ini menunjukkan tidak ada hubungan antara aktivitas fisik dengan status gizi. Hasil $\mathrm{RP}=1,005$ menunjukkan bahwa orang yang tidak berolahraga memiliki peluang untuk mengalami status gizi yang tidak baik 1,005 kali dari pada orang yang berolahraga dan secara statistik tidak bermakna.

\section{B. Pembahasan}

\section{1) Pola Konsumsi Lansia di Panti Sosial Tresna Werdha (PSTW) Unit Abiyoso Yogyakarta Tahun 2011}

Berdasarkan hasil penelitian yang dilakukan di PSTW Unit Abiyoso Yogyakarta, pada 53 responden yang memenuhi kriteria inklusi dan ekslusi yang ditetapkan oleh peneliti, diperoleh data responden yang memiliki pola konsumsi tidak baik sebanyak 15 responden $(28,3 \%)$, sedangkan responden yang memiliki pola konsumsi yang baik sebanyak 38 responden $(71,7 \%)$.

Hasil tersebut kemungkinan dapat disebabkan oleh kemunduran kondisi fisik pada lansia. Kemunduran kondisi fisik, misalnya gigi menjadi ompong, pemasangan gigi palsu yang tidak baik, tangan gemetar (buyutan) dan kelainan fungsi fisik yang lain, maka sering para lansia menjadi sulit mengunyah atau menyuapi dirinya sendiri, akibatnya makanan yang dikonsumsi tidak cukup jumlahnya. ${ }^{8}$ Pola konsumsi yang tidak baik dapat menyebabkan timbulnya masalah dalam kesehatan. Masalah kesehatan yang terjadi dapat berupa kurang gizi. 
2) Aktivitas Fisik Lansia di Panti Sosial Tresna Werdha (PSTW) Unit Abiyoso Yogyakarta Tahun 2011

Hasil penelitian aktivitas fisik (olahraga) yang dilakukan pada responden memperlihatkan bahwa ada 16 responden $(30,2 \%)$ merupakan responden dengan kategori tidak berolahraga, sedangkan 27 responden $(69,8 \%)$ dengan kategori berolahraga. Aktifitas fisik sangat erat kaitannya dengan kebugaran jasmani. Responden dengan kategori aktivitas fisik yang tidak baik, semuanya berasal dari responden yang menderita rasa sakit pada kaki (ngilu) yang menyebabkan mereka susah untuk berjalan bahkan berolahraga. Responden tersebut dapat dikatakan memiliki kebugaran yang tidak baik, karena kebugaran yang baik berarti bahwa seseorang mempunyai cukup tenaga untuk melakukan kegiatan-kegiatan rutin tanpa mengalami kelelahan yang berarti. Aktivitas fisik atau kebugaran yang tidak baik juga dapat dipengaruhi oleh umur, jenis kelamin, keturunan, makanan, kebiasaan merokok, dan latihan. ${ }^{9}$ Tingkat kebugaran jasmani meningkat sampai umur 30 tahun dan setelah usia 30 tahun akan terjadi penurunan tingkat kebugaran secara perlahan. Umumnya pria memiliki tingkat kebugaran jasmani yang melebihi kaum wanita.

\section{3) Status Gizi Lansia di Panti Sosial Tresna Werdha (PSTW) Unit Abiyoso Yogyakarta Tahun 2011}

Status gizi lansia yang ada di PSTW Unit Abiyoso Yogyakarta, menunjukkan bahwa responden dengan status gizi tidak baik ada sebanyak 33 responden $(62,3 \%)$, sedangkan 20 responden $(37,7 \%)$ memiliki status gizi yang baik.

Status gizi yang tidak baik dapat terjadi karena ketidakseimbangan gizi. Ketidakseimbangan gizi yaitu ketidakseimbangan antara konsumsi dan kebutuhan, menyebabkan lansia kurang gizi atau menjadi kegemukan. ${ }^{10}$ Pada lansia yang kurang gizi masalahnya adalah kemampuan indera rasa lidah yang menurun, juga menurunnya kemampuan tubuh mencerna makanan. Pengaruh lingkungan ikut menyebabkan konsumsi makan menjadi rendah, sehingga tidak mencukupi kebutuhan. Demikian sebaliknya, lansia yang kegemukan disebabkan oleh konsumsi yang relatif tetap sedangkan kebutuhan menurun. Penurunan kebutuhan ini disebabkan oleh metabolisme dan aktivitas yang juga ikut menurun.

\section{4) Hubungan Antara Pola Konsumsi dengan Status Gizi pada Lansia di Panti Sosial Tresna Werdha (PSTW) Unit Abiyoso Yogyakarta Tahun 2011}

Hasil analisis bivariat antara pola konsumsi yang dilihat dari tingkat konsumsi energi dengan status gizi pada lansia pada Tabel 6 menunjukkan bahwa dari 15 responden yang memiliki pola konsumsi yang tidak baik dengan status gizi yang tidak baik dengan status gizi yang tidak baik ada sebanyak 8 responden $(24,2 \%)$, dan 7 responden $(35,0 \%)$ memiliki pola konsumsi yang tidak baik dengan status gizi yang baik. 
Hasil analisis bivariat juga menunjukkan bahwa dari 38 responden yang memiliki pola konsumsi yang baik dengan status gizi yang tidak baik ada sebanyak 25 responden $(75,8 \%)$, sedangkan 13 responden $(65,0 \%)$ menunjukkan pola konsumsi yang baik dengan status gizi yang baik, dengan nilai $P$ value $=0,399$ dengan $\mathrm{RP}=0,811$. Artinya, lansia yang pola konsumsinya tidak baik atau tingkat konsumsi energinya $<80 \%$ memiliki peluang untuk mengalami status gizi yang tidak baik 0,811 kali atau $81,1 \%$ dari pada lansia yang pola konsumsinya baik dan secara statistik tidak ada hubungan.

Pola konsumsi pada lansia di PSTW Unit Abiyoso Yogyakarta dinyatakan tidak berhubungan secara statistik dengan status gizi. Hasil penelitian ini kemungkinan disebabkan oleh perubahan umum fungsi pancaindera pada lansia, khususnya penurunan indera perasa dan hilangnya zat gizi pada makanan yang disebabkan karena kesalahan dalam pengolahan dan pemasakan bahan makanan tersebut. Proses pengolahan dan pemasakan bahan makanan banyak berpengaruh terhadap zat gizi bahan makanan tersebut, terutama vitamin dan mineral. ${ }^{11}$ Tingkat kehilangan zat gizi dipengaruhi berbagai faktor, seperti: pemasakan, pencucian, pengilingan, kontak dengan udara dan sebagainya.

Hasil penelitian lain menunjukkan hasil pengukuran tingkat konsumsi energi dengan metode recall 24 jam tidak berhubungan, nilai signifikansi= 0,192 dan Confident Interval $=0,411-1,196$. $^{12}$ Hasil penelitian ini berbeda dengan penelitian lain yang menunjukkan ada hubungan antara tingkat konsumsi energi dengan status gizi $(p=0,00)^{13}$

\section{5) Hubungan Antara Aktivitas Fisik dengan Status Gizi pada Lansia di Panti Sosial Tresna Werdha (PSTW) Unit Abiyoso Yogyakarta Tahun 2011}

Hasil analisis bivariat antara aktivitas fisik dengan status gizi pada lansia pada Tabel 7 menunjukkan bahwa dari 16 responden yang tidak berolahraga dengan status gizi yang tidak baik ada sebanyak 10 responden (30,3\%), dan 6 responden $(30,0 \%)$ tidak berolahraga dengan status gizi yang baik.

Hasil analisis bivariat juga menunjukkan bahwa dari 37 responden yang berolahraga dengan status gizi yang tidak baik ada sebanyak 23 responden (69,7\%), sedangkan 14 responden $(70,0 \%)$ menunjukkan status gizi yang baik, dengan nilai $\mathrm{P}$ value $=0,981$ dengan $\mathrm{RP}=1,005$. Artinya, lansia yang tidak berolahraga memiliki peluang untuk mengalami status gizi yang tidak baik 1,005 kali atau $100,5 \%$ dari pada orang yang berolahraga dan secara statistik tidak ada hubungan.

Aktivitas fisik pada lansia di PSTW Unit Abiyoso Yogyakarta dinyatakan tidak berhubungan secara statistik dengan status gizi. Hal ini kemungkinan disebabkan tidak seimbangnya antara jumlah energi yang dikonsumsi dari makanan dengan aktivitas fisik (olahraga) yang dilakukan. Aktivitas fisik yang dilakukan manusia memerlukan energi dan zat-zat gizi. ${ }^{9}$ Kebutuhan energi dan zat-zat gizi tersebut sebanding dengan kadar aktivitas fisik yang dilakukan. Perbedaan jenis dan bentuk latihan/olahraga yang dilakukan akan berpengaruh pada komposisi zat makanan yang harus diterima. 
Hasil penelitian ini sejalan dengan penelitian lain yang menunjukkan bahwa tidak ada hubungan yang bermakna antara aktivitas fisik dengan status gizi pada anak kost dengan nilai signifikan $=0,429$ dengan $\alpha=0,05$ serta Confident Interval $=0,318-11,048$. $^{12}$ Hasil penelitian yang sama yang dilakukan oleh peneliti lain menunjukkan bahwa tidak ada hubungan yang bermakna $(P>0,05)$ nilai signifikan 0,533 antara pola aktivitas fisik dengan status gizi pada model. ${ }^{14}$

\section{SIMPULAN DAN SARAN}

\section{A. Simpulan}

Berdasarkan hasil penelitian yang telah dilakukan dapat ditarik kesimpulan sebagai berikut:

1) Pola konsumsi lansia di PSTW Unit Abiyoso Yogyakarta Tahun 2011, sebagian besar memiliki tingkat konsumsi energi dengan kategori baik.

2) Aktivitas fisik lansia di PSTW Unit Abiyoso Yogyakarta Tahun 2011, sebagian besar memiliki aktivitas fisik dengan kategori berolahraga.

3) Status gizi lansia di PSTW Unit Abiyoso Yogyakarta Tahun 2011, sebagian besar memiliki status gizi dengan kategori yang tidak baik.

4) Pola konsumsi dengan status gizi pada lansia di Panti Sosial Tresna Werdha (PSTW) Unit Abiyoso Yogyakarta Tahun 2011.

5) Aktivitas fisik dengan status gizi pada lansia di Panti Sosial Tresna Werdha (PSTW) Unit Abiyoso Yogyakarta Tahun 2011.

\section{B. Saran}

1) Bagi Panti Sosial Tresna Werdha Unit Abiyoso Yogyakarta

Hendaknya pihak PSTW Unit Abiyoso Yogyakarta memberikan penyuluhan tentang gizi kepada para staf panti, agar mereka lebih memperhatikan kecukupan gizi bagi lansia yang ada di panti tersebut. Pihak pengurus panti sebaiknya melakukan monitoring menyeluruh terhadap lansia terutama dalam pembagian makanan yang dikonsumsi per lansia agar pembagiannya merata.

2) Bagi Peneliti Lain

Perlu adanya penelitian lanjutan yang serupa dengan variabel penelitian yang lebih lengkap (pendidikan, umur, jenis kelamin dan lain-lain) dan menggunakan metode penilaian gizi selain metode food recall 24 jam. 


\section{DAFTAR PUSTAKA}

1. Anonim, Penduduk Lanjut Usia, www.menegpp.go.id, diakses pada tanggal 20 Maret 2011, Yogyakarta. 2011

2. Hadi, H., Beban Ganda Masalah Gizi dan Implikasinya Terhadap Kebijakan Pembangunan Kesehatan Nasional, Universitas Gadjah Mada, Yogyakarta. 2005

3. Atmarita, Fallah, T.S., Analisis Situasi Gizi dan Kesehatan Masyarakat, Makalah Widyakarya Nasional Pangan dan Gizi, Direktorat Gizi Masyarakat, Jakarta. 2004

4. Azwar, A., Kecenderungan Masalah Gizi dan Tantangan Di Masa Datang, Makalah Advokasi Program Perbaikan Gizi Menuju Keluarga Sadar Gizi, Dirjen Bina Kesehatan Masyarakat, Jakarta. 2004

5. Atmarita, Nutrition Problem In Indonesia, Article, Directorate of Community Nutrition, Jakarta. 2005

6. Marliyati, S.A., Kustiyah, L., Madanijah, S., Kesehatan dan Gizi Di Usia Emas, http:// iirc.ipb.ac.id, diakses pada tanggal 1 April 2011, Yogyakarta. 2008

7. Murti, B., Prinsip dan Metode Riset Epidemiologi, Gadjah Mada University Press, Yogyakarta. 2003

8. Winarno, F.G., Pangan Gizi, Teknologi, dan Konsumen, PT Gramedia Pustaka Utama, Jakarta. 1993

9. Afriwardi, IImu Kedokteran Olahraga, EGC, Jakarta. 2011

10. Waryana, Gizi Reproduksi, Pustaka Rihama. Yogyakarta. 2010

11. Supariasa, I D.N., Bakri, B., Fajar, I., Penilaian Status Gizi, EGC, Jakarta. 2002

12. Fitriani, V., 2010, Hubungan Antara Tingkat Pengetahuan Gizi, Pola Konsumsi dan Aktivitas Fisik dengan Status Gizi Pada Anak Kost Di Kelurahan Warungboto, Kecamatan Umbulharjo, Yogyakarta, Skripsi, Sarjana, Universitas Ahmad Dahlan, Yogyakarta. 2010 